\title{
内蒙古草地样带植物群落生物量的梯度研究
}

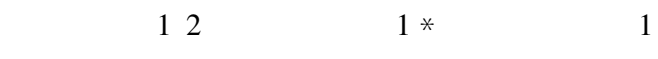 \\ （1 中国科学院地理科学与资源研究所, 北京 100101) (2 中国科学院研究生院 北京 100039)
}

摘 要 采用样带法对内蒙古草地植物群落生物量沿水热梯度的变化特征进行了研究, 并对几种回归方法进行了 比较。一元回归结果表明: 在本样带的限定范围内, 生物量与年均温、 $\geqslant 0{ }^{\circ} \mathrm{C}$ 年积温、 $\geqslant 10{ }^{\circ} \mathrm{C}$ 年积温、年实际日照总 时数等热量因子呈负相关 (年均温的相关性最高), 而与年降水量、年均相对湿度等水分因子呈正相关 (年均相对湿 度的相关性最高) 其中年均温和年均相对湿度对生物量的影响最为显著 二者对生物量的空间变异起着互为消长 的作用，而海拔高度的影响则不显著。多元回归结果表明，作为半干旱区植物生长的主要限制因子，年降水量在大 尺度上对生物量产生影响的途径更为复杂，但其作用不可低估。生物量和地下地上生物量比值会因不同的气候 区、不同的植被类型和物种组成，对环境因子的响应程度不同，在经向、纬向和草地类型梯度上的变化特征也不同。 水热的配比关系要比单一的水分和温度与植物的生长具有更紧密的关系 地下地上生物量比随着水热配比关系的 变化也会呈现出不同的变化规律, 其驱动因子并不一定始终都是降水。也许可以认为 :半干旱/干旱的划分界限是 本研究所涉及的草地样带上生物量和地下地上生物量比值沿草地类型梯度变化的一个转折界限, 在此界限前后, 气候对生物量的主导因素和生物量对此关键因子的响应程度都有所变化。

关键词 内蒙古 草地样带 地下生物量 地上生物量 地下生物量/地上生物量 梯度分析

\section{GRASSLAND BIOMASS OF COMMUNITIES ALONG GRADIENTS OF THE INNER MONGOLIA GRASSLAND TRANSECT}

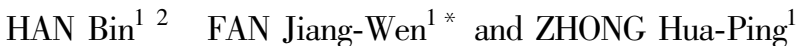 \\ (1 Institute of Geographical Sciences and Natural Resources Research , Chinese Academy of Sciences , Beijing 100101, China) \\ (2 Graduate School of Chinese Academy of Sciences , Beijing 100039 , China)
}

\begin{abstract}
Background and Aims Vegetation transect is an effective method to study the relationship between global change and terrestrial ecosystem. However there are few researches on biomass gradient characters of grassland vegetation and their environmental driving mechanism. The transect measurement was used in this study to analyze biomass gradient change of grassland vegetation in Inner Mongolia. The following questions were tried to answer : (a) How does grassland biomass change along with longitude and latitude as well as water and thermal gradients ? (b) Which climate factors will produce pivotal effect to grassland biomass change? (c) How do climate factors control material production process of grassland ecosystem?

Methods The selection of 49 sample sites was principally defined by a $1900 \mathrm{~km}$ long $\times 150 \mathrm{~km}$ wide transect across the grasslands of Inner Mongolia. Aboveground and belowground biomasses were measured in the sample sites. The correlativity between biomass and climate factors was analyzed using China climate grid database which constructed by Chinese Ecosystem Research Network.
\end{abstract}

Key results Grassland biomass was found to be negatively correlated to mean annual temperature, $\geqslant 0{ }^{\circ} \mathrm{C}$ accumulated temperature, $\geqslant 10{ }^{\circ} \mathrm{C}$ accumulated temperature and annual hours of sunshine. Contrarily it was positively correlated with mean annual precipitation and mean annual relative humidity. Among climate factors, mean annual temperature and mean annual relative humidity effected grassland biomass the most obvious.

Conclusions Aboveground and belowground biomasses present visible change regulation along with longitude and latitude as well as climate gradients. Mean annual precipitation was shown as a key role to grassland biomass although its effect ways were complicated. The study suggested combined and integrated relationships of environment factors should be considered in researches of biomass forming and changing. 
Key words Inner Mongolia , Grassland transect , Aboveground biomass , Belowground biomass , Below-aboveground biomass ratio, Gradient

样带研究被认为是研究全球变化与陆地生态系 统关系最有效的途径之一(Koch et al , 1995;王权， 1997 张新时等,1997;白永飞等,2000;Ni \& Wang， 2004）,尤其对于全球变化驱动因素的梯度分析,样 带研究更具有其特殊价值。因此, 在国际地圈和生 物圈计划 (IGBP) 的两个核心项目 全球变化与陆地 生态系统” (GCTE) 与 古全球变化” (PAGES)中, 都 把样带研究确定为重要的方法。张新时等 (1995) 提 出了中国东北温带森林-草原样带 (NECT)”, 使其 成为国内外研究全球变化与陆地生态系统关系的热 点区域之一, 而在此样带上, 草地生态系统是最重要 的研究内容之一。中国草地以世界草地 6\% 8\% 的面积蓄存了其 $9 \% \sim 16 \%$ 的碳储量, 在全球和干 旱地区的碳蓄积和碳循环中都扮演了重要的角色 (Ni 2002)。为此,于贵瑞 (2003) 在 NECT 的基础上 初步提出了中国草地样带” 的概念和设计, 该样带 自 $135^{\circ} \mathrm{E} 、 48.5^{\circ} \mathrm{N}$ 约成 $28.5^{\circ}$ 角至 $81^{\circ} \mathrm{E} 、 30.3^{\circ} \mathrm{N}$, 贯 穿我国的主要草原区域, 并具有明显的草地类型、气 候和其它生态系列的梯度规律。内蒙古草原位于该 草地样带的东北段, 代表了温性草甸草原向温性草 原、温性荒漠草原、温性草原化荒漠和温性荒漠过渡 的生态系列 基本体现了各草地类型间的梯度变化 趋势, 是研究草地植被水平地带性规律的典型区域, 也是 中国草地样带”上最为重要的区域之一。

生物量是生态系统最基本的数量特征之一, 草 地植物群落生物量的梯度变化研究, 可以为人们了 解草地生态系统的物质能量的分布格局提供基本资 料, 是实现草地持续利用和管理的重要理论依据。 水热条件的结合状况会对植物光合作用和生物量产 生深刻影响(黄富祥等 2001) , 而且群落的分类等级 越低，对环境因子的变化越敏感，研究过程中产生的 不确定性也就越大, 那么在大尺度研究中采用较细 的分类等级便会带来更多的不确定性。在影响东亚 中纬度温带草原的各气候因素中, 水热因子最为关 键, 草地植被生物量通常与降水量呈正相关(张新时 等,1997; 周广胜等,2002;白永飞等,2000;陈佐忠 等, 1988 李博, 2000) , 尤其在干旱地区, 水分对植物 的影响更为明显。对草原植被来说, 地下生物量常 常大于地上生物量, 气候越是干旱, 地下部分所占比 例越大(李博, 2000)。虽然, 目前这方面已有不少相 关研究, 但在已往的研究中, 区域乃至更大尺度上,
从草地样带的角度出发, 探讨草地植物生物量梯度 特征及其与生态环境间的地带性关系的研究仍不多 见, 有关地下生物量方面的研究更是少之又少。为 此, 本文采用样带研究的方法, 分析了内蒙古草地群 落植物地上、地下生物量沿经向、纬向和水热梯度的 变化规律。

\section{1 研究地区概况}

本研究所设置的草地样带位于内蒙古自治区境 内，几乎贯穿由呼伦贝尔高平原、锡林郭勒高平原、 乌兰察布高平原、巴彦淖尔高平原和阿拉善高平原 所构成的整个内蒙古高平原, 地面结构单调、平坦， 起伏和缓、分割轻微。大部分地区属于干旱、半干旱 的大陆性气候。年平均气温自大兴安岭山地向东 南、西南递升，从大兴安岭中山区的 $-3 \sim-5{ }^{\circ} \mathrm{C}$ 逐 渐上升至巴彦淖尔的 $8 \sim 9{ }^{\circ} \mathrm{C}$; 年降水量自东北向西 南递减，从大兴安岭山地和西辽河流域南部山地的 $450 \mathrm{~mm}$ 以上降至阿拉善西部荒漠的 $50 \mathrm{~mm}$ 以下, 差 异非常大,干燥度则递增, 蒸发量大大超过降水量, 全区蒸发量大约相当于年降水量的 3 5 倍, 荒漠区 可高达 200 倍。土壤类型以草原土为主体，土壤剖 面普遍存在钙积层,自东向西依次分布着黑土 $\rightarrow$ 黑 钙土 $\rightarrow$ 栗钙土 $\rightarrow$ 棕钙土 $\rightarrow$ 漠钙土 $\rightarrow$ 灰棕荒漠土, 此 外还有草甸土、风沙土等隐域性土壤。干湿度的东 西差异致使该地区自东向西可明显划分为湿润、半 湿润、半干旱、干旱和极干旱等 5 类气候区,并相应 地形成了温性草甸草原 (建群种和优势种主要为羊 草( Leymus chinensis)、针茅 (Stipa) 属植物、䊁隐子草 (Cleistogenes squarrosa)、冰草 (Agropyron cristatum)、线 叶菊 (Filifolium sibiricum)、委陵菜 (Potentilla)) 属植 物、温性典型草原( 建群种和优势种主要为针茅、羊 草、䊁隐子草、冰草、冷蒿 (Artemisia frigida) )、温性荒 漠草原( 建群种和优势种主要为小型针茅、多根憼 (Allium polyrrhizum)、旱生小半灌木女蒿 (Hippolytia trifida)、猪毛菜 (Salsola collina) )、温性草原化荒漠和 温性典型荒漠等草地植被类型 (章祖同,1990; 张新 时等, 1997; 周广胜等 ,2002)。

\section{2 研究方法}

\section{1 样带的设置}

样带的设计原则为:由东向西能反映草地类型 
的空间更替系列，物种、生态系统以至景观水平上的 经向变化对气候变化的对应有良好的规律性，气候、 地形以及土壤基本具有水平地带性特征,并对气候 与植被有良好的对应;样带沿线具有良好的研究基 础和配套的研究站点。调查样带以草地类型沿东北 $\rightarrow$ 西南方向的梯度变化趋势为主线, 从额尔古纳右 旗至阿拉善右旗(图 1) ,中心样线距离约 $1900 \mathrm{~km}$, 平均宽度约 $150 \mathrm{~km}$, 东西贯穿内蒙古草地植被的地 带性生态系列 基本体现草甸草原 $\rightarrow$ 典型草原 $\rightarrow$ 荒 漠草原 $\rightarrow$ 草原化荒漠 $\rightarrow$ 典型荒漠过渡的变化趋势。 地理区域为 $38^{\circ} 07^{\prime} 35^{\prime \prime} \sim 50^{\circ} 12^{\prime} 20^{\prime \prime} \mathrm{N} 、 101^{\circ} 55^{\prime} 25^{\prime \prime} \sim$ $120^{\circ} 20^{\prime} 46^{\prime \prime} \mathrm{E}$ 。

\section{2 取样方法}

分别在草地最大生物量时期 (2003 和 2004 年 8 ９月）, 沿拟定的调查路线, 大致每 $50 \mathrm{~km}$ 选取一 个非固定样地，共选择地形开阔、有围栏保护且当年 未被采食、具有代表性的天然草地样地 49 个 (图 1), 每个样地随机取 3 个样方, 每个样方面积为 $1 \mathrm{~m} \times 1 \mathrm{~m}$ 。采用草地群落学调查方法, 测定植物种 类组成及其盖度等; 采用收割法获得地上生物量 (包 括凋落物) 棌用土钻法或土柱法 (深度为 $30 \mathrm{~cm}$ ) 获 得根系生物量 ; 对于 (半) 灌木植物, 则在大样方内采 用样株法收集生物量样品, 并同时在大样方内布设 小样方获取草本植物的地上和地下生物量以及灌木 的地下细根生物量。所有样品在 $(80 \pm 5){ }^{\circ} \mathrm{C}$ 的烘箱 内烘干至衡重, 并称其干重。各样地的气象数据主 要来源于中国科学院生态系统网络综合研究中心构 建的全国陆地生态信息气象栅格数据库(表 1)。

\section{3 数据处理和分析方法}

1) 原始数据的校正 对于部分采集时间早于最 大生物量出现季节的数据, 利用已有的内蒙古草地 生长季各月的生物量数据和调整系数 (章祖同， 1990) 求得最大生物量。

2) 数据集的构建 :包括热量因子 (年均温、 $\geqslant 0{ }^{\circ} \mathrm{C}$ 年积温、 $\geqslant 10{ }^{\circ} \mathrm{C}$ 年积温、年实际日照总时数) 和水分 因子(年降水量、年平均相对湿度), 以及通过 GPS 实 地测定获得的地理要素(经度、纬度、海拔高度)。

3) 通过对全部样方数据进行协方差分析的方 法来考察样方间的控制因素和样地间的控制因素对 所采集数据的影响程度, 从而判断数据的随机性与 代表性。

4) 回归分析 利用散点图对相关参数进行一元 回归, 分析比较各要素与各生物量及地下地上生物 量比值间的关系 将各有关要素纳入回归模型 利用
向后剔除法 (Backward elimination) 选择对因变量有 显著影响的参数组合。

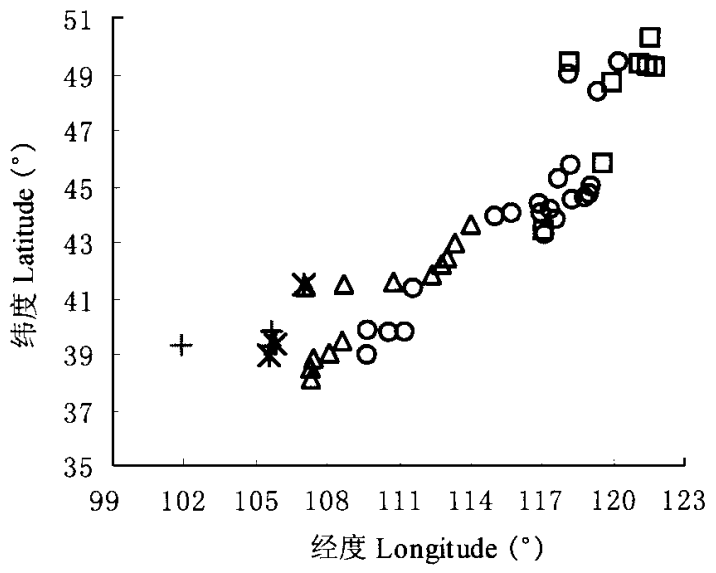

口草甸草原 Meadow steppe

○典型草原 Typical steppe

$\Delta$ 荒漠草原 Desert steppe

× 草原化荒漠 Steppe-desert

+ 荒漠 Desert

\section{图 1 调查样地分布图}

Fig.1 Location of the sample sites

\section{3 研究结果}

\section{1 方差分析结果}

全部样方数据的预分析结果表明，对总生物量、 地上生物量、地下生物量和地下地上生物量比值等 4 个研究对象而言, 样方间的控制因素 (rep)和样地 间的控制因素 $(\mathrm{com})$ 之间均不存在显著的交互作用， 其显著性水平 $p$ 分别为 $0.325 、 0.703 、 0.333$ 和 0.947 均大于 0.05 的置信度。因此,协方差分析的 前提成立。

协方差分析结果表明，样方重复间的数据差异 不显著，即样方间的控制因素对各数据组的影响不 显著 $(p>0.05)$ ，而样地间差异显著 $(p<0.05)$ (表 2 )。各组数据基本符合正态分布。因此, 本研究所 采集的数据集随机性较好，样方重复间因人为和方 法等因素引起的误差可忽略,样方数据的可靠性较 高，而样地间由控制因素引起的差异显著，数据的代 表性较好。

\section{2 生物量分布的经向和纬向特征}

引起植被生物量经向和纬向差异的直接原因是 降水量、温度、海拔高度、土壤等, 但是追本溯源, 地 理特性(包括地理位置、地形、地貌、土壤等) 和海陆 相对位置的差异所引起的物质能量分配才是其根本 所在。另外 影响生物量积累的因素很多, 以往的研 
表 1 全部样地的气象要素统计表

Table 1 Descriptive statistics of meteorological elements for all sampling sites

海拔高度 Altitude $(H)(\mathrm{m})$

年平均气温 Mean annual temperature $(T)\left({ }^{\circ} \mathrm{C}\right)$

年降水量 Annual precipitation $(P)(\mathrm{mm})$

$\geqslant 0{ }^{\circ} \mathrm{C}$ 年积温 Accumulated temperature above zero $\left(A_{0}\right)\left({ }^{\circ} \mathrm{C}\right)$

$\geqslant 10{ }^{\circ} \mathrm{C}$ 年积温 Accumulated temperature above ten degree $\left(A_{10}\right)\left({ }^{\circ} \mathrm{C}\right)$

年平均相对湿度 Mean annual relative humidity $(R)(\%)$

年实际日照总时数 Annual hours of sunshine $(S)(\mathrm{h})$

最小值 Minimum value
586
-2.61
103.92
2215.16
1728
38.75

2617.77
最大值 Maximum value

1634

9.05

394.21

4065.01

3696

70.24

3322.9

表 2 方差分析

Table 2 Tests of between-subjects effects

\begin{tabular}{lcccc}
\hline \multicolumn{1}{c|}{ rep | com } & $\begin{array}{c}\text { 总生物量 } \\
\text { Total biomass }\end{array}$ & $\begin{array}{c}\text { 地下生物量/地上生物量 } \\
\text { Below-aboveground } \\
\text { biomass ratio }\end{array}$ & $\begin{array}{c}\text { 地上生物量 } \\
\text { Aboveground biomass }\end{array}$ & $\begin{array}{c}\text { 地下生物量 } \\
\text { Belowground biomass }\end{array}$ \\
\hline $\begin{array}{l}F \text { 检验计算值 } \\
\text { Computed value of } F \text { test }\end{array}$ & $80.086 \mid 0.326$ & $15.482 \mid 0.218$ & $23.660 \mid 10.474$ & $78.219 \mid 0.236$ \\
$\begin{array}{l}\text { 显著性水平 } \\
\text { Significant level }(p)\end{array}$ & $0.722 \mid 0.000$ & $0.805 \mid 0.000$ & $0.232 \mid 0.000$ & $0.790 \mid 0.000$ \\
\hline
\end{tabular}

rep : 样方间的控制因素(即按样方重复分组) Grouping by repetition com : 样地间的控制因素(即按样地分组) Grouping by sample sites

究大多只采用几个单一的指标进行分析, 难免有失 全面, 而经度和纬度则能综合地反映各个环境因子 与生物量的关系。

由统计结果可以看出 地下、地上生物量和总生 物量在经向和纬向上的分布均有明显的规律性 (图 2)。由西南向东北, 草地群落的地下生物量总体上 呈逐渐升高的趋势。在纬向上(图 2b)，随纬度的升 高, 地下生物量先升高后呈相对下降趋势, 回归分析 表明纬度的变化可以解释地下生物量方差量的 $51.66 \%(p<0.001)$ 。地下生物量的最大值出现在 $44^{\circ} \sim 48^{\circ} \mathrm{N}$ 之间的锡林郭勒的针茅草原, 所涉及的 10 个样地的平均总盖度在 $75 \%$ 以上, 主要种为贝加 尔针茅 (Stipa baicalensis) 和大针茅 (Stipa grandis) (平 均盖度在 $55 \%$ 以上），地下生物量平均为 $2721 \mathrm{~g}$ $\mathrm{m}^{-2}$, 从 $43^{\circ} \mathrm{N}$ 往南进入乌兰察布的荒漠草原后, 地 下生物量开始呈明显的下降趋势。相对而言, 地下 生物量在经向上的变化趋势则显得更具规律性, 属 于线性递增的关系(图 2a)，经度对地下生物量的回 归方程可以解释地下生物量方差量的 $48.69 \%$ ( $p<$ $0.001)$ 。地上生物量在经向和纬向上也表现为递增 趋势, 变化趋势类似于地下生物量, 但其变率要低于 地下生物量, 且变率的变化方向与地下生物量相反 (图 3a,b)。而总生物量沿经向和纬向的变化趋势 则与地下生物量非常相似(图 4a、b)。

3.3 生物量沿水热梯度的变化特征

3.3.1 地下生物量沿水热梯度的变化特征

对全部样地调查资料的统计结果表明, 地下生
物量与各水热因子均有较显著的相关关系。地下生 物量与年降水量和年均相对湿度呈正相关, 而与年 均温、海拔高度、 $\geqslant 0{ }^{\circ} \mathrm{C}$ 年积温、 $\geqslant 10{ }^{\circ} \mathrm{C}$ 年积温和年 日照总时数呈负相关。对地下生物量影响最大的热 量因子是年均温 $(r=-0.678, p<0.001)$, 对其影响 最大的水分因子则是年均相对湿度 $(r=0.628, p<$ 0.001 ）,分别可以解释其方差量的 $51.09 \%$ 和 $41.90 \%(p<0.001)$ (图 2c、d) , 即在内蒙古这样的半 干旱、干旱地区, 温度升高加快蒸散, 湿度增加则减 缓水分抑制，二者对生物量积累的影响互为消长。 海拔高度、年降水量和年实际日照总时数与地下生 物量的相关系数则相对较低 $(|r|=0.359 \sim 0.449)$ 。

\subsection{2 地上生物量沿水热梯度的变化特征}

在区域尺度上，相对于地下较为封闭的系统来 说, 地上生物量的变异则显得更为复杂, 很难找到一 个能对其变化起关键性作用的因子。但是地上生物 量随水热梯度的变化仍然具有比较明显的规律性。 地上生物量除了与海拔高度不存在显著相关性 $(p>0.05)$ 、与年降水量 $(r=0.298, p<0.05)$ 和年实 际日照总时数 $(r=-0.389, p<0.01)$ 的相关性较低 外,与其它各要素均存在中度以上的相关性 $(p<$ $0.005)$ 。其中相关性最高的热量因子和水分因子分 别是年均温和年均相对湿度 $(p<0.005)$, 分别呈负 相关和正相关, 即地上生物量与年均温表现为递减 关系, 而与年均相对湿度则表现为递增趋势, 变化趋 势类似于地下生物量, 但其变率要低于地下生物量, 且变率的变化方向与地下生物量相反 (图3c、d)。 


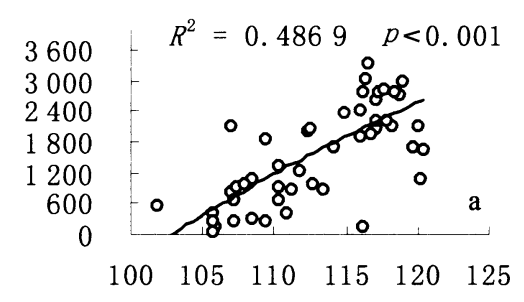

经度 Longitude $\left({ }^{\circ}\right)$

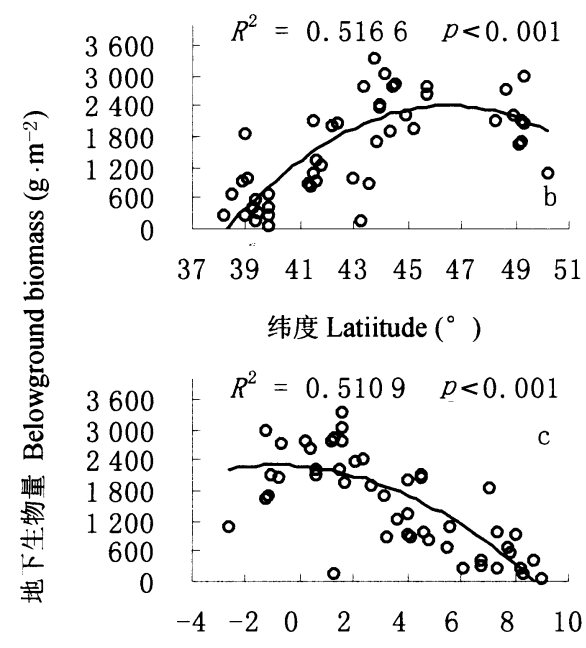

年均温度 Mean annual temperature $\left({ }^{\circ} \mathrm{C}\right)$

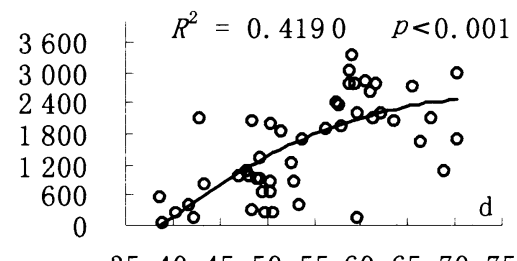

$\begin{array}{lllllllll}35 & 40 & 45 & 50 & 55 & 60 & 65 & 70 & 75\end{array}$

年均相对湿度 Mean annual relative humidity(\%)

图 2 地下生物量沿水热梯度的经向及纬向变化趋势

Fig.2 Changing trend of belowground biomass with that of precipitation , temperature along gradients of longitude or latitude

但各回归曲线所表现出的规律性相对较差,年降水 量和年日照总时数对地上生物量方差量的贡献只有 $18.96 \%$ 和 $15.87 \%$,其它各要素(海拔高度除外)的 贡献值则在 $32.02 \% \sim 38.07 \%$ 之间。

\subsection{3 总生物量沿水热梯度的变化特征}

地下生物量是生物量的重要组成部分 (Coupland, 1992 ; 姜恕等,1985; ; 宇万太和于永强,2001) ,直 接影响地上部分生物量的积累。本研究的 49 个样 地中地下生物量在总生物量中所占比例最小为 $52.58 \%$, 最大为 $97.51 \%$, 平均为 $88.26 \%$, 其中 $0 \sim$ $10 \mathrm{~cm}$ 的根系生物量就占了总生物量的 $23.49 \%$ $73.60 \%$, 平均为 $53.77 \%$ 。因此 地下生物量也会在 很大程度上影响总生物量的梯度变化特征，总生物 量沿水热梯度的经向和纬向变化趋势都和地下生物

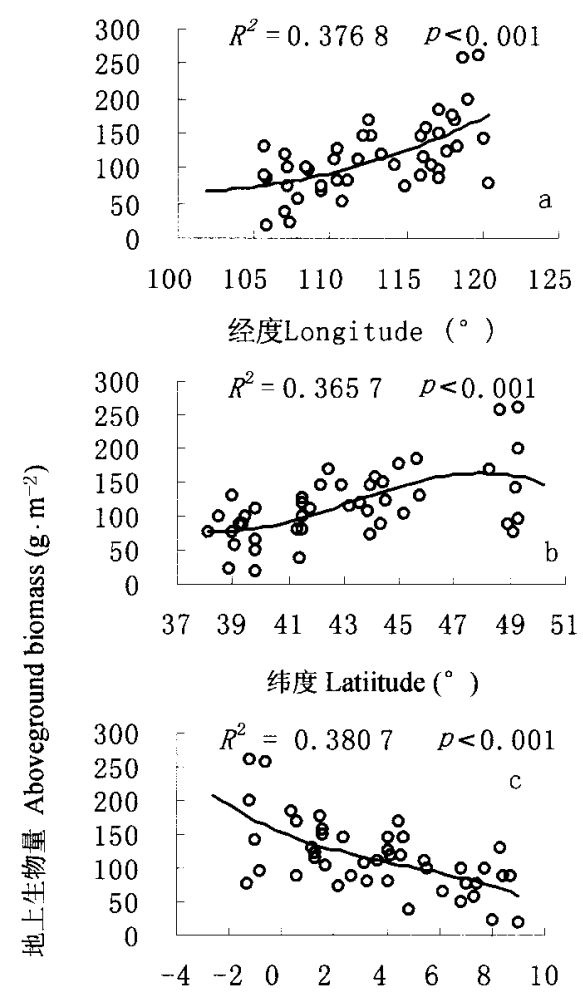

年均温度 Mean annual temperature $\left({ }^{\circ} \mathrm{C}\right)$

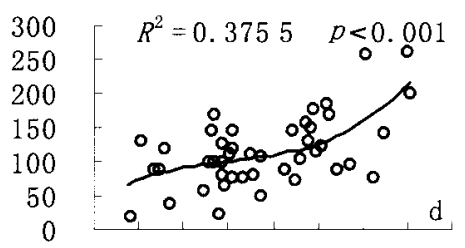

$354045 \quad 50 \quad 5560657075$

年均相对湿度 Mean annual relative humidity $(\%)$

图 3 地上生物量沿水热梯度的经向及纬向变化趋势

Fig.3 Changing trend of aboveground biomass with that of precipitation , temperature along gradients of longitude or latitude

量的变化趋势非常相似(图 4)，各要素与总生物量 也都有着较显著的相关关系, 其相关系数与地下生 物量与各要素的相关系数也很接近, 差值在 0.002 0.013 之间、平均 0.006 , 最为相关的热量因子和水 分因子也是年均温和年均相对湿度, 判定系数为 $51.30 \%$ 和 $41.81 \%(p<0.001)$ 。

\section{4 地下生物量/地上生物量的梯度变化}

过去的几十年中, 生态学家为寻求更为可行有 效的净初级生产力 (NPP) 的估算方法付出了巨大的 努力, 目前有关地上生物量和 NPP 的定量研究已得 到了较为长足的发展 (Paruelo et al., 1997 ; Raich et al . , 1997 ; Sala \& Austin , 2000) ,但是地下生物量的 定量研究仍显匮乏, NPP 在地下的分配规律一直没 有得到很好的解释 ( Lauenroth ,2000)。而对于地 


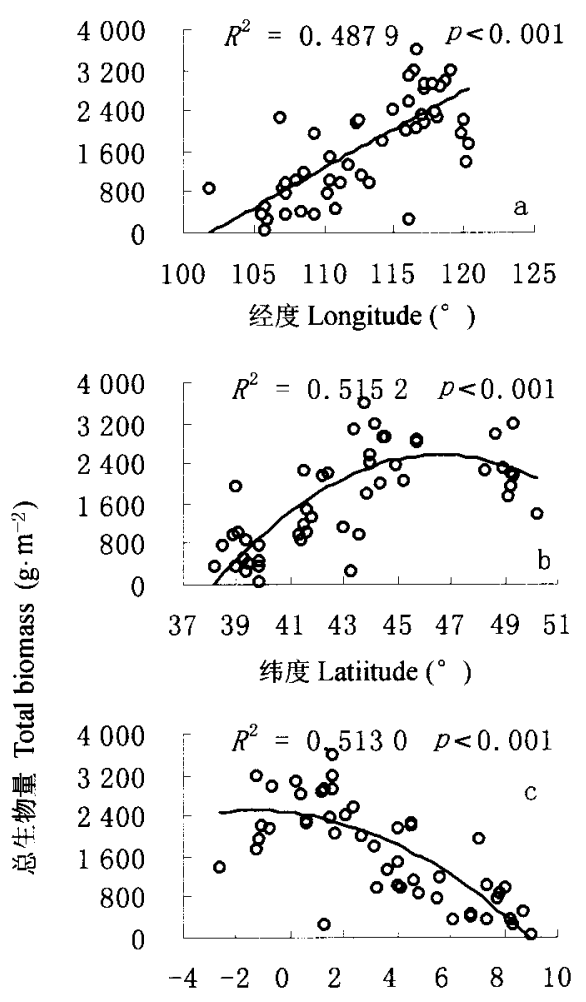

年均温度 Mean annual temperature $\left({ }^{\circ} \mathrm{C}\right)$

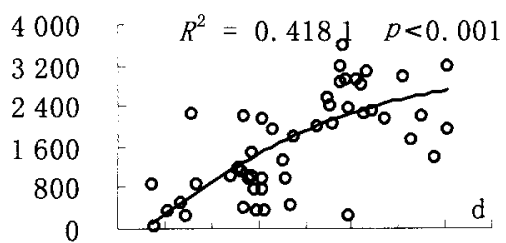

$\begin{array}{lllllllll}35 & 40 & 45 & 50 & 55 & 60 & 65 & 70 & 75\end{array}$

年均相对湿度 Mean annual relative humidity (\%)

图 4 总生物量沿水热梯度的经向及纬向变化趋势

Fig.4 Changing trend of total biomass with that of precipitation , temperature along gradients of longitude or latitude

下地上生物量比的研究则有助于通过地上生物量对 地下生物量进行估算,从而有助于进一步深入理解 草地植被在地球化学循环中所起的作用。

受到地上生物量变异复杂性的影响, 各要素与 地下地上生物量的比值的相关系数 $|r|$ 均在 $0.361 \sim$ 0.411 之间，属于低度相关，对该比值方差的解释量 也均在 $30 \%$ 以下，可见，地下地上生物量比值对气 候的响应机制更为复杂, 仅用单个因子表达有失全 面。在经向上 地下地上生物量的比值随经度增加 基本呈递增趋势 (图 5a)，即从西向东，地下地上生 物量比值逐渐增大; 而在纬向上, 此比值则出现了两 次转折 (图 5b) 即荒漠 $\rightarrow$ 典型草原的递增阶段和典 型草原 $\rightarrow$ 草甸草原的递减阶段。相对而言, 热量因
子中, $\geqslant 10{ }^{\circ} \mathrm{C}$ 年积温与地下地上生物量比值具较高 的负相关性。 $\geqslant 10{ }^{\circ} \mathrm{C}$ 年积温是草地植被开始积极 生长的温度, 且在大部分地区与辐射差额值有很好 的线性负相关关系，在一定尺度上能反映当地的蒸 发能力 (陈志银, 2000), 因此, 我们可以理解为在内 蒙古地区 蒸散率越高地下地上生物量比值越低。
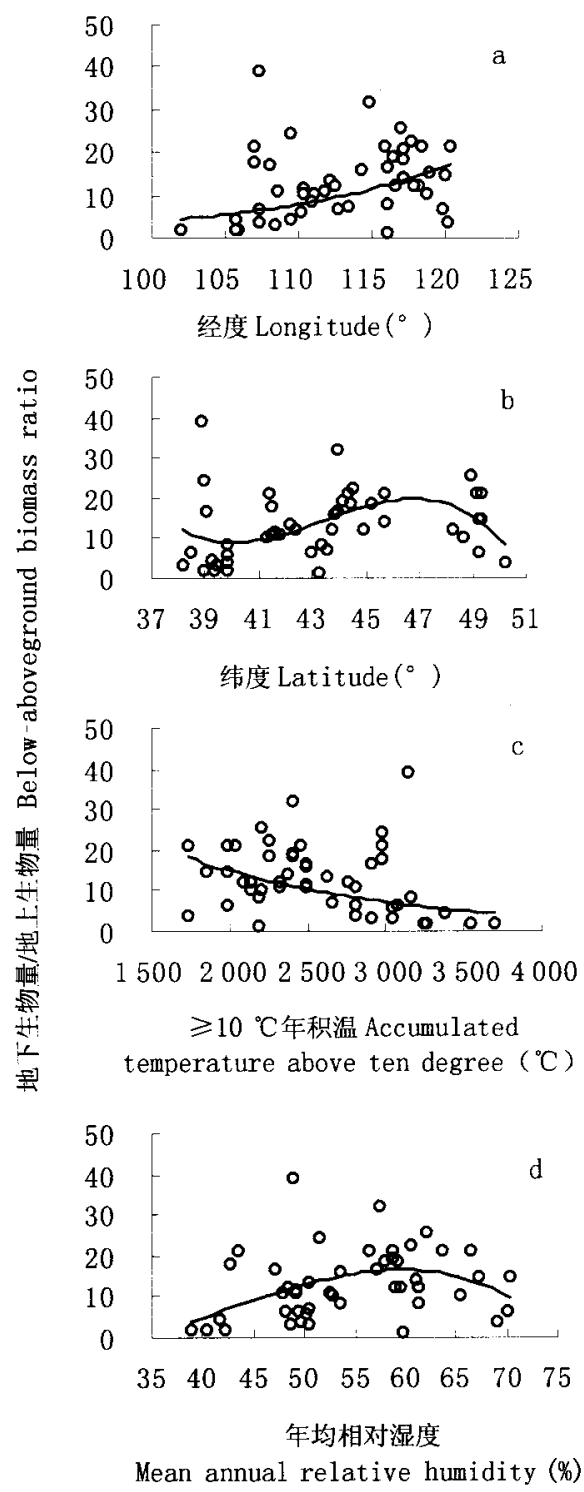

图 5 地下生物量/地上生物量的梯度变化趋势

Fig.5 Changing trend of below-aboveground biomass ratio along gradients of factors

在水分因子中，仍是年均相对湿度占据了主要地位， 地下地上生物量比值先是随着湿度的增加而增大， 到一定的临界值后, 则逐渐减小（图 5d), 年降水量 也与地下地上生物量比值存在相似的关系。

3.5 生物量沿草地类型生态系列的分布特征 
表现在草地类型的生物量变异上,总生物量沿 着草甸草原、典型草原、荒漠草原、草原化荒漠和典 型荒漠的生态系列逐级降低 (图 6), 其中草甸草原 最高, 荒漠最低,其平均值依次为 2305.61 、 $2199.46 、 1129.29 、 956.51$ 和 $475.05 \mathrm{~g} \mathrm{~m}^{-2}$ 。其变 率有两个较为明显的峰值, 即由典型草原向荒漠草 原的变化和由草原化荒漠向荒漠的变化,变化量都 在前一类型的 $50 \%$ 左右, 相对来说, 草甸草原和典 型草原间的差距最小, 其变化量仅是草甸草原的 $4.6 \%$ 。

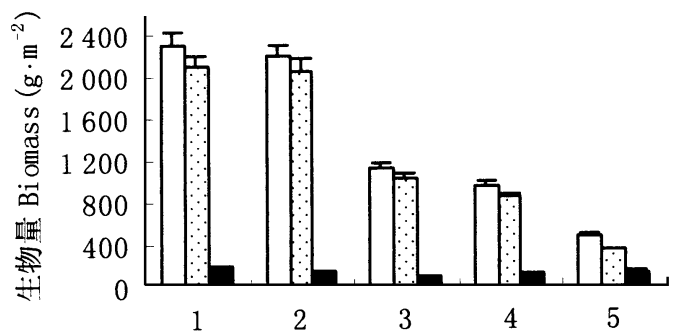

口总生物量Total biomass

口地下生物量Belowground biomass

地上生物量Aboveground biomass

图 6 生物量在草地类型上的分异

Fig.6 Biomass on different grassland type

1. 草甸草原 Meadow steppe 2. 典型草原 Typical steppe 3. 荒漠 草原 Desert steppe 4. 草原化荒漠 Steppe-desert 5. 典型荒漠 Desert

地上生物量从草甸草原向荒漠的变化序列从数 据的绝对值来看, 生物量是先降后升的, 分别为 $206.81 、 138.18 、 99.90 、 113.35$ 和 $136.30 \mathrm{~g} \mathrm{~m}^{-2}$,低谷 出现在荒漠草原而非荒漠。但是地上生物量在总生 物量中的比例却是个递增的过程 (除典型草原略有 降低外), 并且其比例的变率在经过了由草甸草原向 典型草原、荒漠草原的平缓变化后，在草原化荒漠和 荒漠出现了陡增的趋势(图 7)。

地下生物量在 5 种草地类型上的变化趋势与地 上生物量的变化规律相反。地下生物量在典型草原 向荒漠草原过渡和草原化荒漠向荒漠过渡中出现了 两个变率的峰值,分别减少了前一类型生物量的 $50.06 \%$ 和 $59.82 \%$, 草甸草原与典型草原间的生物 量差异最小, 这与总生物量的变化规律相似。由图 6 和图 7 两种规律性分析可以看出,相对于生物量 的绝对值而言，生物量在地下、地上的分配更能客观 的体现出各植被类型间的差异和变化规律。

地下地上生物量的比值表现在草地类型上，则 是经历了从草甸草原向典型草原递增再向荒漠草 原、草原化荒漠、荒漠递减的过程 (图 8)，地下部分
均大于地上部分, 最高值出现在典型草原 基于 5 类 草原该比值各样地的均值分别为: $12.82 、 15.42$ 、 12.42 .7 .14 和 2.68 ,变率的变化较为平缓。

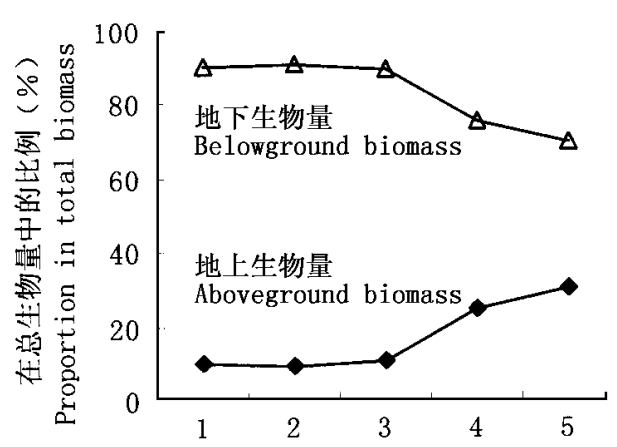

图 7 生物量分配在草地类型上的变化

Fig.7 Biomass distribution on different grassland type $1 \sim 5$ :同图 6 See Fig. 6

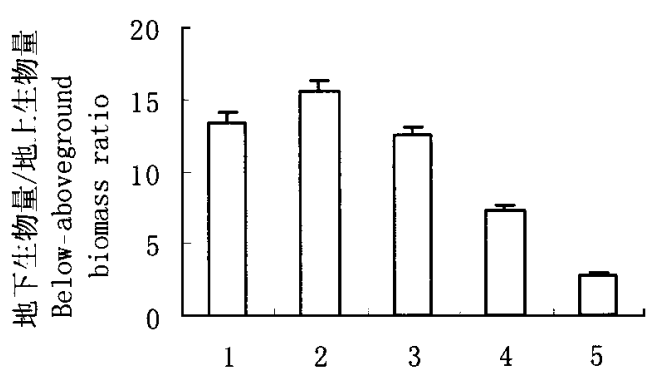

图 8 地下地上生物量比值在草地类型上的变化 Fig. 8 Below-aboveground biomass ratio on different grassland type $1 \sim 5$ :同图 6 See Fig. 6

\section{4 讨 论}

各生物量在经向和纬向上均呈现出明显的递增 趋势, 具有区域性变化特征的气象因素也与生物量 的变化存在着某种内在的联系, 在本样带的限定范 围内, 生物量及地下地上生物量比与热量因子成负 相关，而与水分因子成正相关。在一元回归分析中， 年均温和年均相对湿度是对生物量影响最为显著的 热量因子和水分因子，而对地下地上生物量比影响 最大的热量因子和水分因子分别是 $\geqslant 10{ }^{\circ} \mathrm{C}$ 年积温 和年均相对湿度。

以往研究通常认为降水量是干旱、半干旱地区 的主要限制性因子(李博, 2000)。本研究样带是遵 循草地类型的生态演替系列来设置的，结果却显示 中国草地样带内蒙古段基本分布在 $200 \sim 400 \mathrm{~mm}$ 等 降水量线间、 $300 \mathrm{~mm}$ 等降水量线左右, 也就是说降 
水量所体现的水分梯度并不是很典型，那么仅仅用 生物量沿降水梯度的变化来反映样带植被对干旱程 度的响应规律就稍显片面。另外, 运用一元回归方 程只能从单方面考虑单个因素对生物量的影响，而 忽略了因素间交互作用的影响。利用所有要素对各 组生物量数据进行向后剔除法 (Backward elimina- tion)的多元回归分析，与前面的一元回归结果进行 比较后发现, 在一元回归分析中总是处于相关系数 较小位置的年降水量, 却始终与年均温一起出现于 向后剔除法对生物量所篮选出的参数组合中, 而在 一元回归分析中比较突出的年均相对湿度却总是被 剔除(表 3 )。

表 3 多元线性回归分析

Table 3 Statistics of regression for biomass with given factors by backward elimination

\begin{tabular}{|c|c|c|c|c|c|c|c|c|}
\hline \multirow{3}{*}{$\begin{array}{c}\text { 回归方法 } \\
\text { Regression method }\end{array}$} & \multicolumn{2}{|c|}{$\begin{array}{l}\text { 总生物量 } \\
\text { Total biomass }\end{array}$} & \multicolumn{2}{|c|}{$\begin{array}{c}\text { 地下生物量/地上生物量 } \\
\text { Below-aboveground } \\
\text { biomass ratio } \\
\end{array}$} & \multicolumn{2}{|c|}{$\begin{array}{c}\text { 地上生物量 } \\
\text { Aboveground biomass }\end{array}$} & \multicolumn{2}{|c|}{$\begin{array}{c}\text { 地下生物量 } \\
\text { Belowground biomass }\end{array}$} \\
\hline & 全回归法 & 后剔除法 & 全回归法 & 句后剔除法 & 全回归法 & 后剔除法 & 全回归法 & 向后剔除法 \\
\hline & Enter & Backward & Enter & Backward & Enter & Backward & Enter & Backward \\
\hline $\begin{array}{l}\text { 复相关系数 } \\
\text { Mutiple correlation coefficient }(R)\end{array}$ & 0.790 & 0.767 & 0.489 & 0.404 & 0.642 & 0.603 & 0.792 & 0.769 \\
\hline $\begin{array}{l}\text { 判定系数 } \\
\text { Determination coefficient }\left(R^{2}\right)\end{array}$ & 0.624 & 0.588 & 0.239 & 0.163 & 0.412 & 0.363 & 0.627 & 0.591 \\
\hline $\begin{array}{l}\text { 调整的判定系数 } \\
\text { Adjusted determination coefficient }\left(R_{\mathrm{a}}{ }^{2}\right)\end{array}$ & 0.537 & 0.551 & 0.064 & 0.087 & 0.276 & 0.305 & 0.541 & 0.554 \\
\hline $\begin{array}{l}\text { 显著性水平 } \\
\text { Significant level }(p)\end{array}$ & 0.000 & 0.000 & 0.238 & 0.091 & 0.008 & 0.000 & 0.000 & 0.000 \\
\hline $\begin{array}{l}\text { 选入的参数 } \\
\text { Variables entered }\end{array}$ & 全部 All & $E, T, P, A_{0}$ & 全部 All & $E, T, P, A_{0}$ & 全部 All & N, $, P, P$ & 全部 All & $E, T, P, A_{0}$ \\
\hline
\end{tabular}

$E$ 经度 Longitude $N$ 纬度 Latitude $T$ 年均温 Mean annual temperature $P$ :年降水量 Annual precipitation $A_{0}: \geqslant 0{ }^{\circ} \mathrm{C}$ 年积温 Accumulated temperature above zero $S$ :年实际日照总时数 Annual hours of sunshine

这种分析的结果与小尺度的试验结果在某种程 度上找到了契合点，即水分是限制干旱和半干旱区 植物生长和分布的主要限制因子 (黄富祥等, 2001)。 比较全回归和向后剔除法的回归结果后发现，对总 生物量变异的解释, 全部要素的综合影响为 $62.4 \%$, 而经度、年均温、年降水量和 $\geqslant 0{ }^{\circ} \mathrm{C}$ 年积温的综合作 用就达到了 $58.8 \%$ ，且调整后的判定系数 $R_{\mathrm{a}}{ }^{2}$ 也是 后者高于前者, 也就是说, 后者组成的回归方程比前 者的更优。地上生物量和地下生物量也存在着同样 的结论, 但是对二者比值的回归结果却不理想, 其显 著性大于 0.05 , 方程不足以采纳。综合相关分析和 回归分析的结果发现, 在内蒙古地区, 各要素中海拔 高度对草地植被生物量的影响是最小的。

由向后剔除法得到的各方程分别为：

总生物量

$Y_{1}=-19531.0+255.407 E+428.956 T-$

$5.084 P-2.601 A_{0}$

地上生物量

$Y_{2}=2309.313-21.548 N-35.523 T-$

$0.658 P-0.312 S$

地下生物量

$Y_{3}=-20630.5+262.864 E+448.558 T-$
$5.126 P-2.578 A_{0}$

式中 : $E$ 为经度, $N$ 为纬度, $T$ 为年均温, $P$ 为 年降水量, $A_{0}$ 为 $\geqslant 0{ }^{\circ} C$ 年积温, $S$ 为年实际日照总时 数。

一般认为草地植被地下生物量与地上生物量的 比值在 2 13 之间, 荒漠草原最低, 矮草草原可达 13 ,但是低温、干旱和放牧能使该值增加 (Coupland, 1979)。沈禹颖等 (1995) 的研究结果则把该值上限 提到了 16.87 。本研究的各个样地均取自天然草 地, 虽有围栏封育但仍存在放牧影响; 不同研究者在 生物量的采样方法、对样地和钻点的选取、对植被分 类的确定以及在最大生物量出现时间的认定上会存 在差异。以上原因以及样带研究存在的跑点取样难 度都决定了本研究结果与以往研究中根据固定的生 态站点多年完全封育的天然草地所得到的结果有所 不同。

以往的多数研究认为, 在草原生物量中，气候越 是干旱 地下部分所占比例越大(李博,2000), 可是 本研究结果却表明, 沿着内蒙古草地样带的植被类 型梯度 地下地上生物量比的最高值出现在典型草 原, 然后向荒漠草原、草原化荒漠、荒漠逐级降低, 最 低值出现在荒漠。我们认为, 前人多用根冠比 
(Root/shoot ratio) 来推算或者代替地下地上生物量 比 (Below-aboveground biomass ratio)，但是根冠比与地 下地上生物量比在概念和测算上都有着本质的区 别。根冠比指植物地下部分与地上部分干重或鲜重 的比值, 涉及的往往是单种单株植物而且是主要种 或者建群种的活体部分,而地下地上生物量比则不 仅仅包括前述的 根” “冠”部分，还包括已调落的悾 存器官 地下地上生物量比又在相当程度上反应了 生物量对后者的分配关系(Noy-Meir,1973) ; 此外，对 于种群或者群落乃至生态系统等较大尺度的植被的 研究, 所测定的是整个样方内所有植物种的地下、地 上生物量, 包括某些地上部分远大于地下部分的次 生种, 如菌类植物等。这在相当程度上决定了地下 地上生物量比值要与根冠比有很大不同。目前已有 的相关研究多集中于 根冠比” 的范畴, 因此, 其研究 结果与群落水平上的地下地上生物量比不具有可比 性。

在上述前提下, Noy-Meir (1973) 认为:不同生活 型的根冠比存在很大的不同, 对于农作物和木本植 物，往往越干旱根冠比越高，但对于干旱区的多年生 草本植物来说却不尽然; 高的地下地上生物量比也 不是荒漠化演替中植被的普遍特征，其比值的高低 变化和生活型或温度的关系也许更强于和干旱程度 的关系。Gill 等(2002)的研究表明地上最大生物量 和年均温与地下生物量存在一定的相关关系。本研 究中 草甸草原 (年降水量平均 $351.81 \mathrm{~mm}$ ) 和典型 草原 (311.83 mm) 大部分处于半干旱区 (干燥度 $1.50 \sim 4.00$, 年降水量 $250 \sim 500 \mathrm{~mm}$ ) (席承藩, 1981 ), 荒漠草原 (238.43 mm)、草原化荒漠 (162.59 $\mathrm{mm})$ 和荒漠 $(127.35 \mathrm{~mm}$ ) 则主要处于干旱区。不同 的气候区, 不同的植被类型和物种组成, 草地群落生 物量对环境因子的响应程度不同，地下地上生物量 比随着水热配比关系的变化也会呈现出不同的变化 规律, 其驱动因子并不一定始终都是降水。在湿润 至半干旱区, 降水量能相对满足植物的生长需要, 植 物在生长过程中所遇到的水分胁迫不是普遍现象， 那么一旦出现水分抑制，便会产生比较明显的后果 ; 进入干旱区后, 植物物种发生明显的地带性变化, 具 有相应生存对策的耐旱植物开始占据主导位置, 其 中不乏抗旱性的灌木和半灌木, 其木质部分的形成 在相当程度上加大了地上生物量的比例, 而另一方 面, 沿着水热梯度降水量的减少和变率则因基数的 较小化而显得不再那么具有突变性, 这时, 水分对于 植物的抑制作用就不再首当其冲, 因为植物的生存
对策决定了它不仅是吸取更多的水分和养分, 更是 储存水分和积累干物质, 而高的积温和大的变温都 是促进地上干物质积累的有利因素, 高温又在其生 态幅内 那么温度促进生长的作用反倒得到了更好 的反应。机理上的具体原因目前尚没有更充分的数 据辅佐进行深入的解释。

那么，我们也许可以认为:半干旱/干旱的划分 界限是本研究所涉及的草地样带上生物量和地下地 上生物量比值沿草地类型梯度变化的一个转折界 限，在此界限前后，气候对生物量的主导因素和生物 量对此关键因子的响应程度都有所变化。水热的配 比关系要比单一的水分和温度与植物的生长具有更 紧密的关系, 而这种配比率的地带性变化与植物生 物量之间具有什么样的导数关系呢? 目前尚缺乏一 个或一组可以有效反映二者关系，从而能够更深入 地表达水、热对植物生物量积累的复杂消长关系的 指标。此假设还需进一步的验证。

\section{5 小 结}

总生物量、地上生物量、地下生物量以及地下地 上生物量的比值在经向和纬向上均呈现出一定的规 律性, 但是由于本样带的设置是从东北向西南成锐 角延伸的, 因此要把纬向与经向的变化趋势进行重 叠整合后分析 结果发现从西部低纬度向东部高纬 度, 生物量呈递增趋势。对内蒙古地区而言, 海拔高 度对生物量的影响不显著, 而年均温和年均相对湿 度是对生物量影响显著的两个水热因子，二者对生 物量的变异起着互为消长的作用, 而作为半干旱区 植物生长的主要限制因子, 年降水量在大尺度上对 生物量产生影响的途径则更为复杂, 不能只凭单一 的相关系数和一元回归就得出结论。多元回归的结 果显示, 经度、年均温、年降水量和 $\geqslant 0{ }^{\circ} \mathrm{C}$ 年积温的 集合与总生物量和地下生物量显著相关, 纬度、年均 温、年降水量和年实际日照总时数的集合与地上生 物量相关。地下地上生物量比值沿着草甸草原向典 型草原、荒漠草原、草原化荒漠、荒漠的生态系列渐 变的过程是先升后降的, 这与草地类型所处的气候 区和水热配比关系有关。相关系数是相关分析中经 常被用来说明两个变量之间线性相关程度的指标， 但是在多元回归分析中, 由于多元变量的复杂性, 简 单的相关系数并不能准确全面地反映出变量间的相 关程度, 本研究利用多元回归的方法进行比较的结 果也说明了这一点。结合回归模型拟合的情况来 看, 对于生物量形成与变异的影响因子的研究, 应该 
综合考虑各因素间的相互作用对其产生的影响。年 降水量对内蒙古草地生物量有着最根本的影响作 用, 且其影响途径更为复杂。此外, 年均温和 $\geqslant 0{ }^{\circ} \mathrm{C}$ 年积温也与生物量密切相关, 并直接影响了草地植 被的生长和当地的蒸散率, 而 $\geqslant 0{ }^{\circ} \mathrm{C}$ 年积温与降水 量的结合则在很大程度上影响了生物量的积累。生 物量的形成与积累有着复杂的生理机制, 不仅与各 气象要素密切相关, 还与土壤、地形、地貌、样品采集 地的小气候、土地利用方式等有关，因此野外采样和 室内分析的结果仍存在很大的不确定性。这就决定 了在以后的研究中必须在方法上有所突破。

\section{参 考 文 献}

Bai YF (白永飞), Li LH (李凌浩), Wang QB (王其兵), Zhang LX (张丽霞), Zhang Y (张炎), Chen ZZ (陈佐忠) (2000). Changes in plant species diversity and productivity along gradients of precipitation in the Xilin river basin, Inner Mongolia. Acta Phytoecologica Sinica (植物生态学报), 24, 667 - 673. (in Chinese with English abstract)

Chen ZY (陈志银) (2000). Agrometeorology (农业气象学). Zhejiang Unerversity Press, Hangzhou, 159. (in Chinese)

Chen ZZ (陈佐忠), Huang DH (黄德华), Zhang HF (张鸿芳)

(1988). Study on the model of interrelation between belowground biomass and precipitation of Aneurolepidium chinense and Stipa grandis grassland in Inner Mongolia region. In: Inner Mongolia Grassland Ecosystem Research Station, Chinese Academy of Sciences(中国科学院内蒙古草原生态系统定位站) ed. Research on Grassland Ecosystem No.2(草原生态系统研究(第 2 集)). Science Press, Beijing, 20-25. (in Chinese)

Coupland RT(1979). Grassland Ecosystems of the World: Analysis of Grasslands and Their Uses. Cambridge University Press, Cambridge.

Coupland RT (1992). Mixed prairie. In: Coupland RT ed. Grasslands of the World. Cambridge University Press, Cambridge, 151 -182 .

Gill RA, Kelly RH, Parton WJ, Day KA, Jackson RB, Morgan JA, Scurlock JMO, Tieszen LL, Castle JV, Ojima DS, Zhang XS(2002) . Using simple environmental variables to estimate belowground productivity in grasslands. Global Ecology \& Biogeography, 11, 79-86.

Huang FX (黄富祥), Gao Q (高琼), Fu DS (傅德山), Liu ZD (刘振铎) (2001). Relation between climate variables and the aboveground biomass of Thymus mongolicus-Stipa bungeana community in steppe of Ordos Plateau, Inner Mongolia. Acta Ecologica Sinica (生态学报) ,20, 1339-1346. (in Chinese with English abstract)

Jiang S(姜恕), Qi QH(戚秋慧), Kong DZ(孔德珍)（1985）. The primary research about biomass of the Aneurolepidium chinense and Stipa grandis grassland community. In: Inner Mongolia Grassland Ecosystem Research Station, Chinese Academy of Sciences (中国科学院内蒙古草原生态系统定位站) ed. Research on Grassland Ecosystem No.1 (草原生态系统研究(第 1 集)). Science Press, Beijing, 12-22. (in Chinese)
Koch GW, Scholes RJ, Steffen WL, Vitousek PM, Walker BH (1995). The IGBP Terrestrial Transects: Science Plan (IGBP Reports No.36). IGBP, Stockholm.

Lauenroth WK (2000). Methods of estimating belowground net primary production. In: Sala OE, Jackson RB, Mooney HA, Howarth RW eds. Methods in Ecosystem Science. Springer, New York, $58-71$.

Li B (李博) (2000). Ecology (生态学). Higher Education Press, Beijing, 270-276. (in Chinese)

Ni J(2002) . Carbon storage in grassland of China. Journal of Arid Environments, 50, $205-218$.

Ni J, Wang GH (2004). Northeast China Transect (NECT) : tenyear synthesis and future challenges. Acta Botanica Sinica (植物 学报), 46, 379- 391 .

Noy-Meir I(1973) . Desert ecosystems: environment and producers. Annual Review of Ecology and Systematics, 4, 25 - 49.

Paruelo JM, Epstein HE, Lauenroth WK, Burke IC (1997) . ANPP estimates from NDVI for the Central Grassland Region of the United States. Ecology, 78, $953-958$.

Raich JW, Russell AE, Vitousek PM (1997). Primary productivity and ecosystem development along an elevational gradient on Mauna Loa, Hawaii. Ecology, 78, 707-721 .

Sala OE, Austin AT(2000). Methods of estimating aboveground net primary productivity. In: Sala OE, Jackson RB, Mooney HA, Howarth RW eds. Methods in Ecosystem Science. Springer, New York, $31-43$.

Shen YY(沈禹颖), Yan SG(阎顺国), Zhu XY (朱兴云), Zhao $\mathrm{Y}$ (赵银) (1995). The primary productivity of saline pastures in Hexi Corridor. I. The seasonal dynamics of above- and underground biomass. Acta Prataculturae Sinica (草业学报), 4(2), 44 - 50. (in Chinese with English abstract)

Wang Q (王权) (1997). Advance research on terrestrial transects. Advance in Earth Sciences (地球科学进展), 12, 43-50. (in Chinese with English abstract)

Xi CF (席承藩) (1981). Summary of Natural Regionalization in China (中国自然区划概要). Science Press, Beijing. (in Chinese)

Yu GR (于贵瑞) (2003). Global Change, Carbon Cycle and Storage in Terrestrial Ecosystem (全球变化与陆地生态系统碳 循环和碳蓄积). China Meteorological Press, Beijing, 84. (in Chinese)

Yu WT (宇万太), Yu YQ (于永强) (2001). Advance in the research of belowground biomass. Chinese Journal of Applied Ecolo$g y$ (应用生态学报), 12,927-932. (in Chinese with English abstract)

Zhang XS (张新时), Yang DA (杨奠安) (1995). Allocation and study on global change transect. Quaternary Sciences (第四纪研 究) ,1, 43-52. (in Chinese with English abstract)

Zhang ZT (章祖同) (1990). Inner Mongolia Grassland in China (内蒙古草地资源). Inner Mongolia People's Press, Huhhot, 31 - 37, 318. (in Chinese)

Zhou GS (周广胜), Wang YH (王玉辉), Jiang YL (蒋延玲) (2002). Global change and water-driven IGBP-NECT, Northeast China. Earth Science Frontiers (地学前缘), 9, 198 - 215. (in Chinese with English abstract) 